Images du travail, travail des images

$5 \mid 2018$

Le travail à l'écran : mise en scène des groupes professionnels par les médias

\title{
Le choix à Grégoire
}

Nadège Abadie

\section{(2) OpenEdition}

Journals

Édition électronique

URL : http://journals.openedition.org/itti/913

DOI : 10.4000/itti.913

\section{Éditeur}

Université de Poitiers

\section{Référence électronique}

Nadège Abadie, "Le choix à Grégoire », Images du travail, travail des images [En ligne], 5 | 2018, mis en ligne le 01 février 2018, consulté le 14 avril 2021. URL : http://journals.openedition.org/itti/913 ; DOI : https://doi.org/10.4000/itti.913

Ce document a été généré automatiquement le 14 avril 2021.

Images du travail, travail des images 


\section{Le choix à Grégoire}

\section{Nadège Abadie}

\section{Le choix à Grégoire}

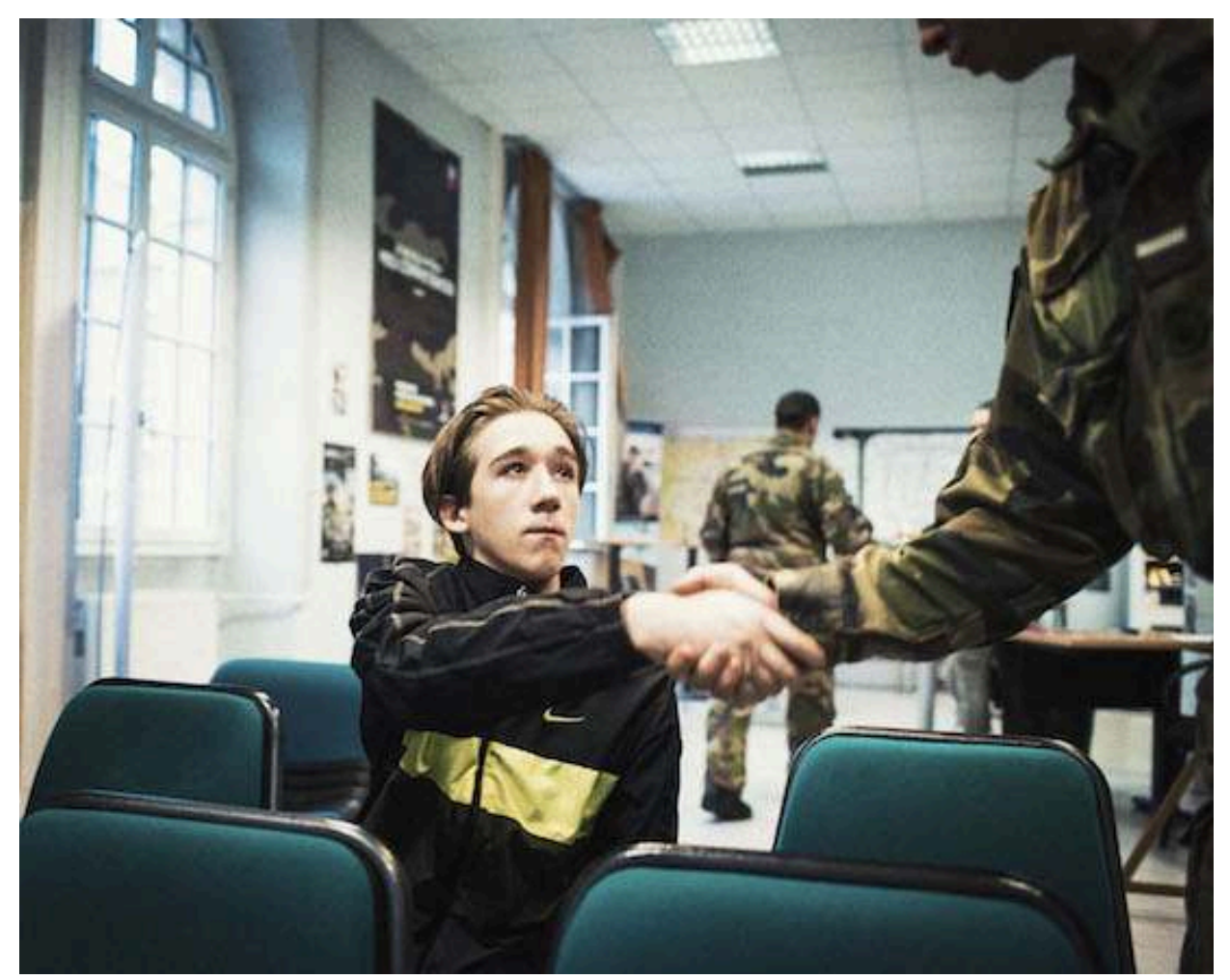

(c) Nadège Abadie

1 Le choix à Grégoire c'est aussi celui de Sébastien, d'Omilpha, d'Éloïse, d'Océane, de Jules... futurs militaires.

2 J'ai réalisé cette image en décembre 2015. Elle fait partie du premier volet d'une série documentaire réalisée pour la mission photographique La France vue d'ici, menée par Mediapart et ImageSingulières. Je m'intéressais à trois choix de vie atypiques chez les 
jeunes : ceux qui veulent devenir militaires, ceux qui souhaitent être ordonnés prêtres et ceux qui s'installent en tant que paysans. J'avais choisi ces trois voies car elles convoquaient un imaginaire fort, des stéréotypes et des préjugés auxquels je voulais me confronter photographiquement et sociologiquement. Moi, athée, antimilitariste et citadine. Aussi, elles allaient me permettre de raconter visuellement, par leur puissance évocatrice, ce que c'est que de faire un choix.

3 Alors, j'ai arpenté les CIRFA (Centres de Formation et de Recrutement des Forces Armées) de France à partir de 2013. J'ai photographié des visages, des rendez-vous, des silences, des regards, l'attente des corps, les signatures de contrats, des doutes, des sourires, de l'angoisse. J'ai attendu. Je connais bien la vidéo de présentation montrée aux jeunes qui poussent la porte du CIRFA pour la première fois. J'ai attendu avec eux. Un jour de décembre, assise sur les chaises face à la télévision diffusant la fameuse vidéo, j'ai vu entrer Grégoire. C'était la première fois qu'il se rendait au CIRFA. Il était venu avec sa mère, comme beaucoup d'autres. Il avait 17 ans. Il s'est assis sur une des chaises face à l'écran. Je l'ai regardé. Je savais ce qui allait se passer. J'ai attendu.

Le recruteur est arrivé, d'un pas décidé, et s'est présenté à Grégoire. C'est à ce momentlà que j'ai déclenché. Deux fois. Puis ils sont partis dans son bureau. J'ai tout de suite regardé sur mon écran d'appareil. Je savais que j'avais quelque chose mais je ne savais pas exactement quoi. Deux images : une où Grégoire me regarde, seul; et cette image.

Elle contient tout. Tout ce que j'ai tenté de rassembler au cours de mes différentes rencontres et qui forment ma série photographique. En ce sens, elle est holistique. L'un assis, l'autre debout, la mollesse et la poigne, la virgule du jogging Nike et le motif guerrier du treillis, Grégoire, seul, entouré de cinq chaises vides, et l'amorce anonyme du militaire. L'un est dans la lumière, l'autre dans l'ombre. Le regard, légèrement flou, de Grégoire renseigne sur le degré d'inconnu du chemin qu'il s'apprête à prendre. Et c'est ce qui me fascine toujours quand je regarde cette image. Être heureux, c'est apprendre à choisir, sa voie, son métier, sa manière de vivre et d'aimer. Donner un sens à sa vie n'est pas facile. C'est prendre une direction. La photographie m'a permis de rendre visible ce moment de bascule, imperceptible à l'œil nu, racontant l'ordinaire de nos grandes décisions.

\section{AUTEUR}

\section{NADĖGE ABADIE}

Nadège Abadie, née en 1988, est photographe réalisatrice. Elle développe des projets qui allient photographies, sons, vidéos et textes, s'attachant à raconter des vies, des parcours, des trajectoires humaines. Elle travaille en commande pour la presse nationale et internationale. Ses travaux sont exposés à ImageSingulières à Sète, au Pilori à Niort, à la galerie C-FAL à Genève, aux Promenades Photographiques de Vendôme ainsi qu'à la Galerie Temple à Paris. Suite au succès de son court-métrage 32 boulevard de Magenta, elle réalise en 2017 son premier documentaire Le Point de rosée coproduit par De Films en Aiguille et France Télévisions. En cours d'écriture de 
deux nouveaux documentaires, elle est également enseignante en Écritures audiovisuelles à l'École Nationale Supérieure Louis-Lumière.

Site : nadegeabadie.fr 